\title{
Vulnerability Assessment in Technology-Based Systems: A Case Study in Tehran Gas Supply Network
}

\section{Esmaeil Shoja $^{1}$ (D), Mohammad Hassan Cheraghali,**iD, Alireza Rezghi Rostami ${ }^{3}$, Alireza Derakhshani $^{2}$}

${ }^{1}$ PhD Candidate, Department of Technology Management, South Tehran Branch, Islamic Azad University, Tehran, Iran

2 Associate Professor, Department of Industrial Management, South Tehran Branch, Islamic Azad University, Tehran, Iran

${ }^{3}$ Assistant Professor, Department of Industrial Management, South Tehran Branch, Islamic Azad University, Tehran, Iran

* Corresponding Author: Mohammad Hassan Cheraghali, Department of Industrial Management, South Tehran Branch, Islamic Azad University, Tehran, Iran.Email: mhcheraghali6@gmail.com

Received: $27 / 10 / 2020$

Accepted: $12 / 12 / 2020$

How to Cite this Article:

Shoja E, Cheraghali $M H$, Rezghi

Rostami A, Derakhshan A.

Vulnerability Assessment in

Technology-Based Systems: A

Case Study in Tehran Gas

Supply Network. J Occup Hyg Eng. 2021; 8(1): 19-25. DOI: 10.29252/johe.8.1.19

\section{Abstract}

Background and Objective: A variety of natural, man-made, and technological hazards threaten the resilience of a system and make it vulnerable. Therefore, the present study aimed to assess the vulnerability of the gas distribution network in the city of Tehran.

Materials and Methods: This cross-sectional study was performed in town board stations (TBSs) in one of the gas distribution areas of Tehran during 2019-2020. This study was conducted based on the approach of identifying hazard and threat centers and vulnerability assessment. The vulnerability assessment was performed using a three-dimensional matrix consisting of three factors, including the probability of occurrence, the severity of the damage, and the extent of preparedness for the threat.

Results: In total, six hazard or threat sources were identified in the studied TBSs, including insulating joints, shut-off valves, station pipelines, sensors, regulators, and filters. The vulnerability caused by these six sources was estimated at 36, 30, 120,112, 40, and 140, respectively. Based on the results, insulating joints, shut-off valves, and regulators presented threats of level two (medium), and station pipelines, sensors, and filters were level three threats (severe). The vulnerability index was in the range of 101-215.

Conclusion: The results indicated that the resilience of TBSs in this area are threatened by six major sources. Furthermore, the results of the vulnerability assessment of these TBSs revealed that the resilience to these threats is relatively low. Therefore, special attention should be paid to the reduction of vulnerability in this area of the gas distribution network.

Keywords: Gas Distribution Network; Resilience; Town Board Stations; Vulnerability Assessment 
do1: $10.29252 /$ johe.8.1.19

\title{
ارزيابى آسيبيذيرى در سيستمهاى تكنولوزىمحور: يك مطالعه موردى در شبكه
} كازرسانى شهر تهران

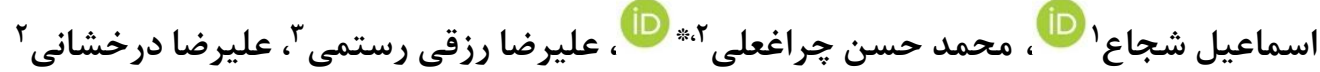 \\ ' انشجوى دكترى، كروه مديريت تكنولوزى، واحد تهران جنوب، دانشخاه آزاد اسلامى، تهران، ايران

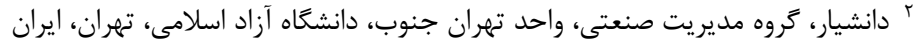

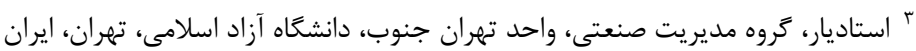

* نويسنده مسئول: محمدحسن جراغعلى، گروه مديريت صنعتى، واحد تهران جنوب، دانشعاه آزاد اسلامى، تهران، ايران. ايميل:mhcheraghali6@gmail.com

\section{جكيده}

سابقه و هدف: انواع خطرات طبيعى، انسانساز و تكنولوزيكى مى تواند تابآورى يك سيسته را تهديد نموده

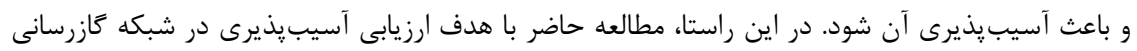

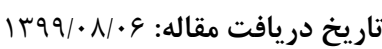

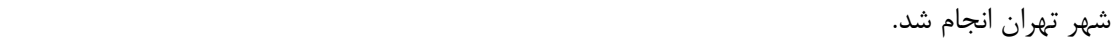
مواد و روشىها: اين مطالعه مقطعى در ايستكاههاى تقليل فشار درون شهرى در يكى اندى از مناطق كازرسانى

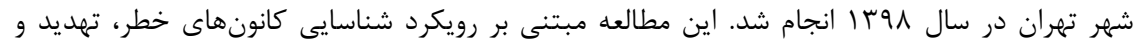

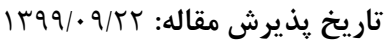

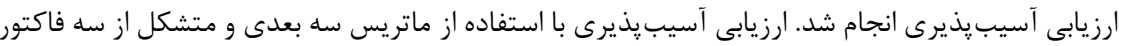

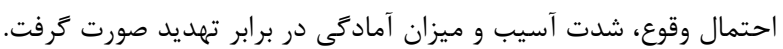

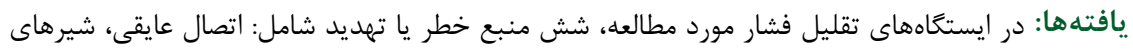

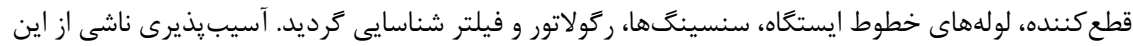

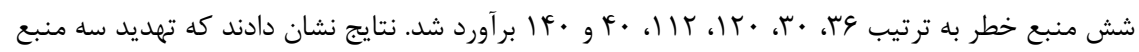

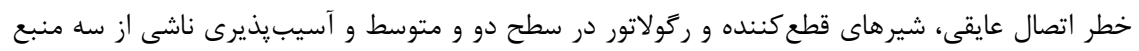

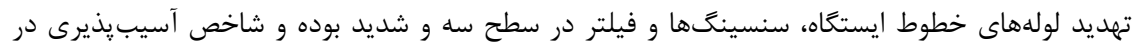

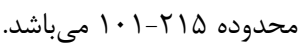

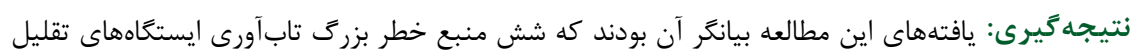



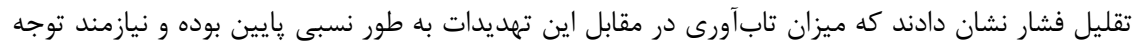

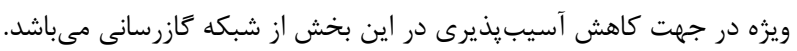
تمامى حقوق نشر براى دانشكاه علوم يزشكى همدان محفوظ است.

وازَّان كليدى: ارزيابى آسيبيذيرى؛ ايستكاههاى تقليل فشار درون شهرى؛ تابآورى؛ شبكه كازرسانى



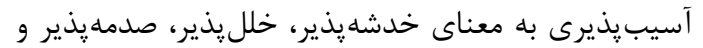



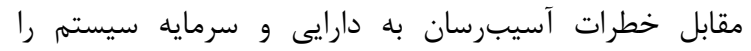

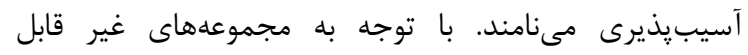

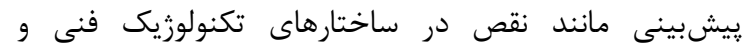

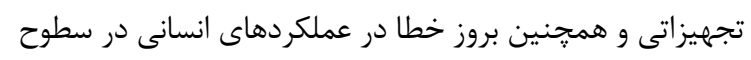
مختلف سازمانى، سطح آسيب در صنايع و سازمانها به مقدار

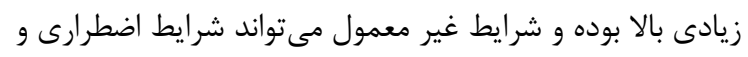

مجله مهندسى بهداشت حرفهاى، دوره ^، شماره ا، بهار ..1F
مقدمه يكى از مهمترين خالشها براى دستيابى به اهداف توسعه پايدار در سيستمهاى تكنولوزىمحور، تهديداتى مانند سوانح


آسيبهاى عمدى و حوادث ناشى از خطاى انسانى كه در تعامل

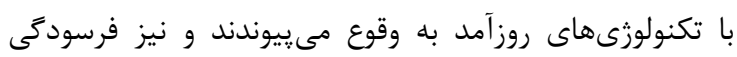

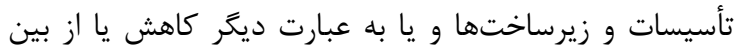
رفتن قابليت اعتماد تكنولوزى مورد استفاده مىباشد. نكته حائز

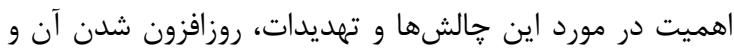
افزايش ميزان ريسك اين تهديدات يا آسيب پيذيرى اين سيستمها 


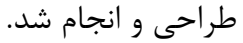

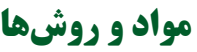

مطالعه حاضر يك بررسى مقطعى و تحليل نظاممند بود كه

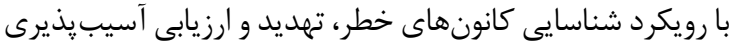

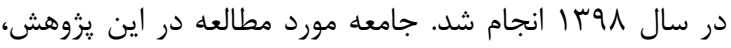
يكى از مناطق كازرسانى شهر تهران و نمونه

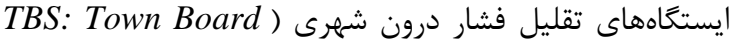
Station

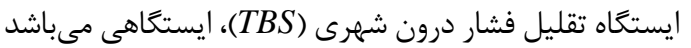

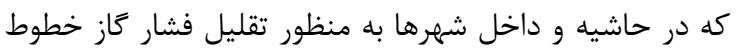
تغذيه از فشار متوسط به فشار ضعيف نصب كرديده است. تاز

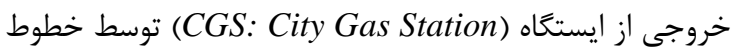

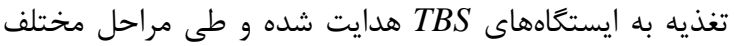
فشار آن شكسته شده و تقليل مى يابد. فشار ورودى به به مرايت

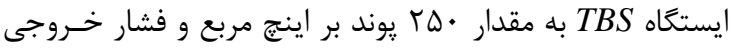

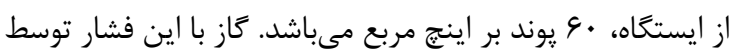

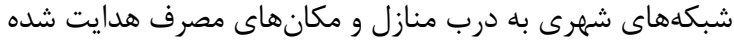

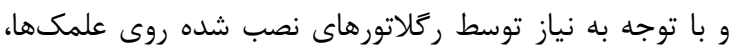

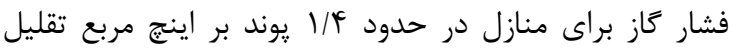

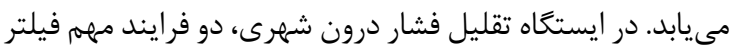
و تميز كردن كاز و همجنين شكستن يا تقليل فشار كاز انجام

مراحل اجراى مطالعه

اين مطالعه در سه كام اجرا شده است (شكل ().

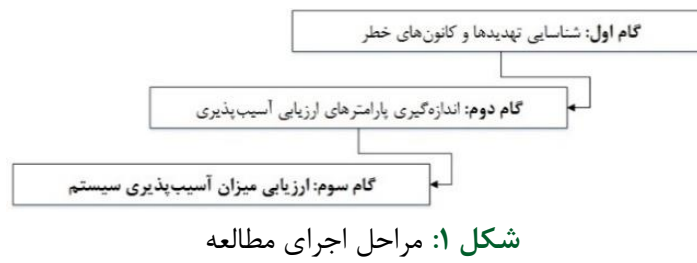

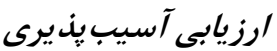
ارزيابى آسيبذيذيرى در اين مطالعه با استفاده از سه فاكتور

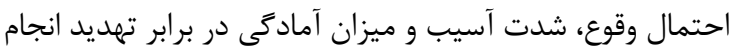

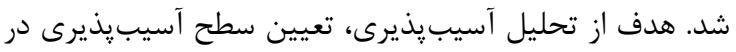

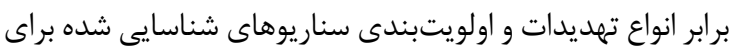

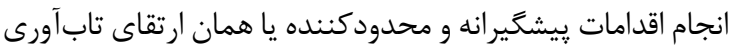

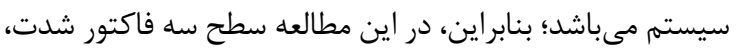

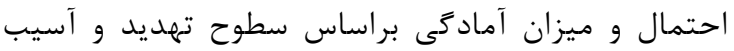
قابل تحمل توسط سازمان مورد مطالعه (شركت كاز

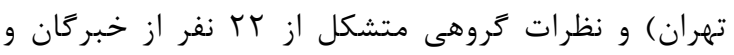
مديران اين سازمان تعيين گرديد (جدول (1). شايان ذكر آنران
بحران را ايجاد نموده و يا منجر به فاجعه شود [ـ-هـ].

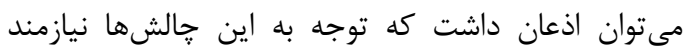

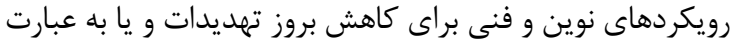

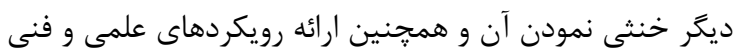

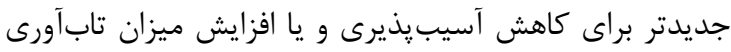

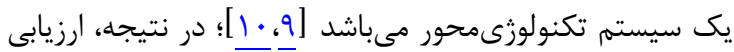

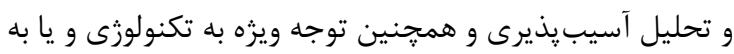

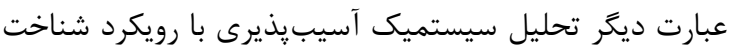

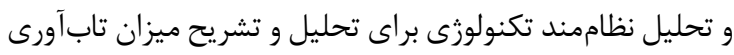

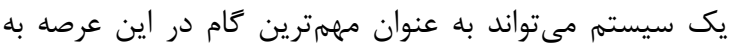

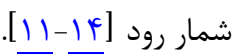
در واقع سيستم يا صنعت تابآور، شبكهاى پايدار از سيستمهاى كالبدى و نيروى انسانى است. سيستمهاى كالبدى،

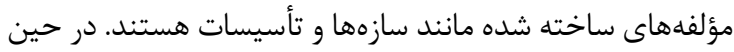
حوادث يا تهديدات مختلف، سيستمهاى كالبدى بايد باند باقى بمانداند و در فشارهاى شديد نيز به عملكرد خود ادامه دهند. ساختار

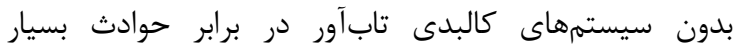

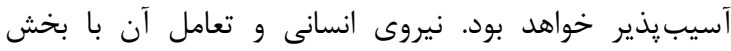
تكنولوزى، مؤلفههاى اجتماعى و نهادى يكى سيستم يا ساختار

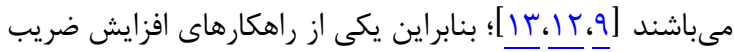

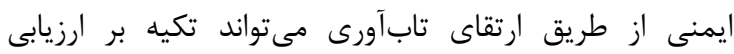

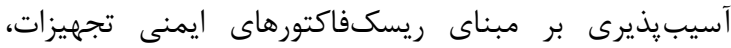

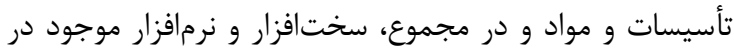

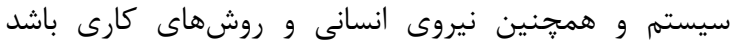

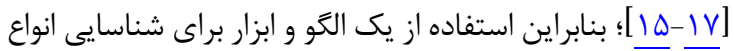

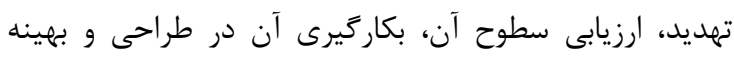

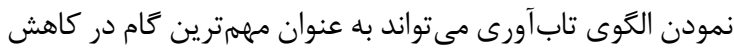

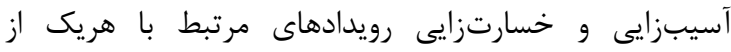

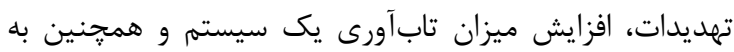

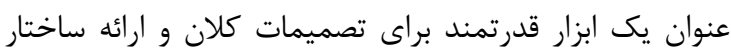
مناسب در راستاى ارتقاى سطح تابآورى و قابليت اعتماد سيستمها در يك سيستم تكنولوزىمحور مورد توجه و استفاد إناه

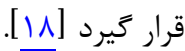
كازرسانى به عنوان يكى از نيازهاى حياتى، شريان اصلى إلى

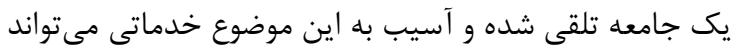

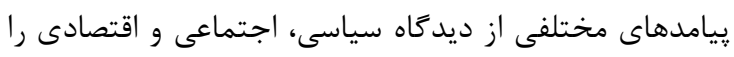

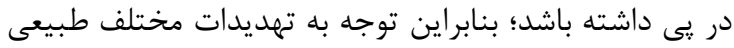

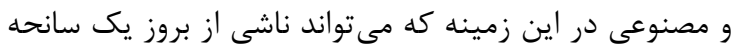

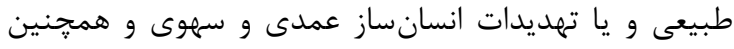

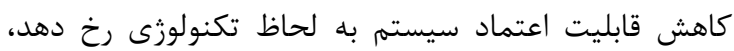

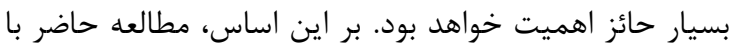

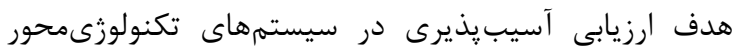
براساس يك مطالعه موردى در شبكه كازرسانى شهر تهران 
جدول ا: تعيين سطوح فاكتورهاى فاكتور شدت، احتمال وقوع و ميزان آمادكى إنى إندان

\begin{tabular}{|c|c|c|c|}
\hline آمادگى (درصد) & 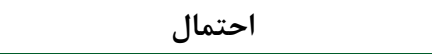 & شدت (آسيب انسانى و اقتصادى) & سطح \\
\hline $9 \cdot<$ & احتمال بروز كمتر از ه درصد مىباشد & بسيار جزئى؛ > • ب ميليون تومان & 1 \\
\hline$\wedge \cdot-9 \cdot$ & احتمال بروز كمتر از · ل درصد مىباشد & جزئى و عدم بسترى؛ • له-· ميليون تومان & t \\
\hline$\vee \cdot-\Lambda \cdot$ & احتمال بروز كمتر از • † درصد مىباشد & 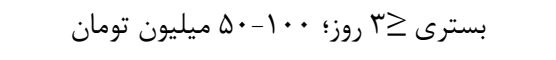 & r \\
\hline$\Delta \cdot-\gamma \cdot$ & احتمال بروز كمتر از rQ درصد مىباشد & 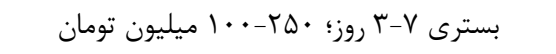 & r \\
\hline$\varphi \cdot-\Delta \cdot$ & احتمال بروز كمتر از • • درصد مىباشد & 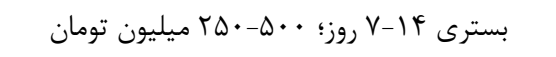 & $\Delta$ \\
\hline$r \cdot-r \cdot$ & احتمال بروز كمتر از • • درصد مىباشد & بسترى بيش از دو هفته؛ •VD- - •D ميليون تومان & द \\
\hline$r \cdot-r \cdot$ & احتمال بروز كمتر از •ه درصد مىباشد & منجر به نقص عضو جزئى؛ •/VD-1/ • ميليارد تومان & $\checkmark$ \\
\hline $1 \cdot-r \cdot$ & احتمال بروز كمتر از •ع درصد مىباشد & منجر به نقص عضو حياتى؛ ه/|--•/ ميليارد تومان & $\wedge$ \\
\hline$\Delta-1 \cdot$ & احتمال بروز كمتر از VD درصد مىباشد & مرك | نفر؛ •/ץ-|山/ ميليارد تومان & 9 \\
\hline$\Delta>$ & احتمال بروز بالاتر از VD درصد مىباشد & مرى > ا نفر؛ > ب ميليارد تومان & $1 \cdot$ \\
\hline
\end{tabular}

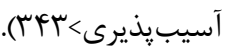

\section{كافته.}

نتايج اين مطالعه در دو بخش شناسايى منابع خطر و تهديد و

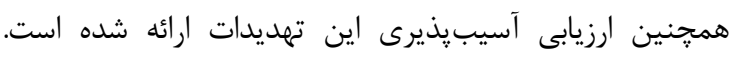

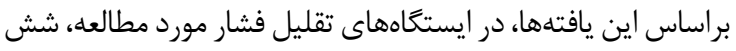

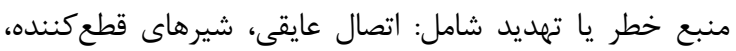

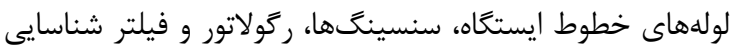

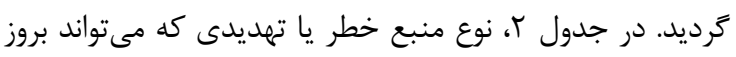

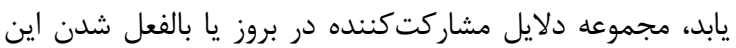

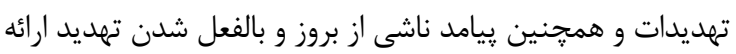

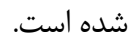
نتايج ارزيابى آسيب يذيرى منابع خطر و تهديد شناسايى

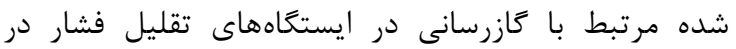

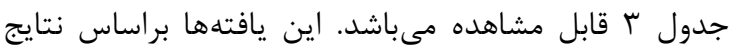

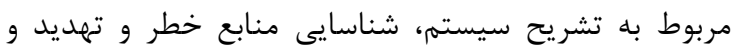

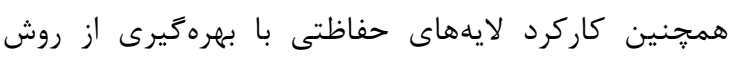

است كه انتخاب عدد براى هريك از فاكتورهاى احتمال،

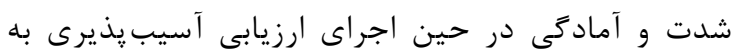

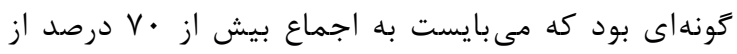

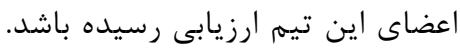

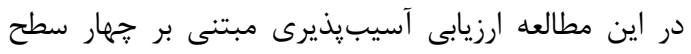

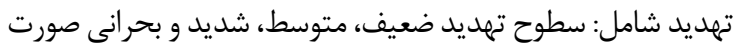

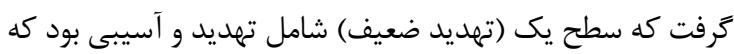

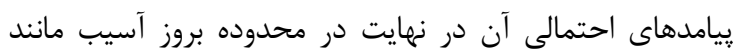

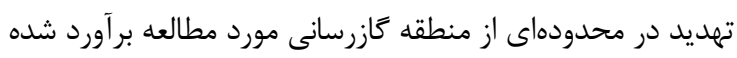

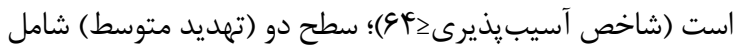


محدوده بروز آسيب؛ اما در داخل منطقه كَازرسانى مورد نظر بود داند

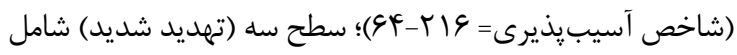
تهديدى بود كه مىتواند تقريباً كل شبكه گازرسانى مورد مطالعه

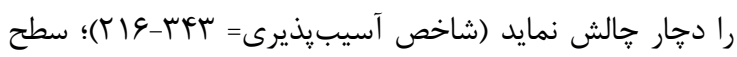

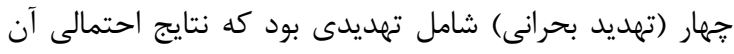

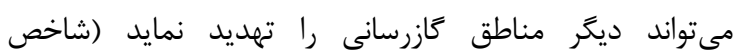

جدول r: شناسايى منابع خطر و تهديد در ايستخاههاى تقليل فشار مورد مطالعه

\begin{tabular}{|c|c|c|}
\hline يِيامد و آسيب & علل بروز تهديد & منبع خطر /تهديد \\
\hline 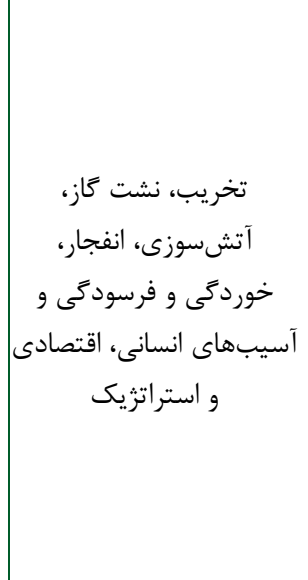 & 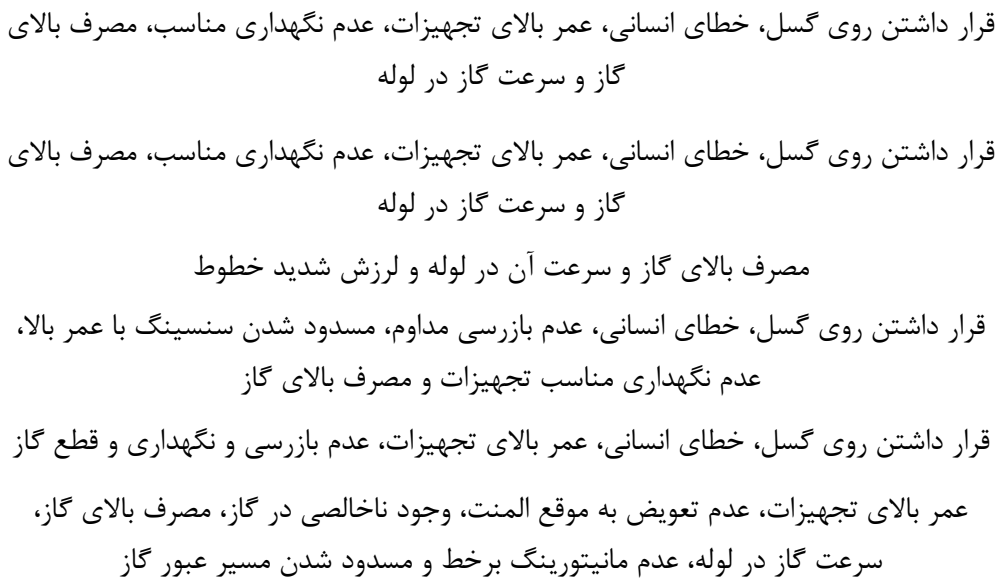 & 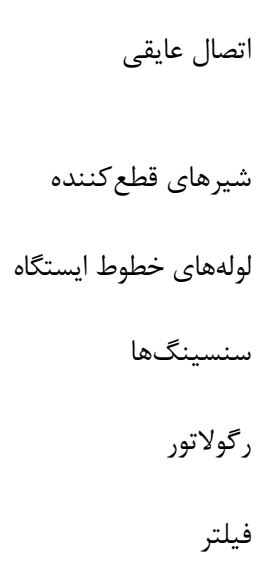 \\
\hline
\end{tabular}




\begin{tabular}{|c|c|c|c|c|}
\hline آسيب پيذيرى & آمادَى & احتمال & شدت & منبع خطر /تهديد \\
\hline re & r & f & r & اتصال عايقى \\
\hline$r$. & r & $\Delta$ & r & شيرهاى قطع كنينده \\
\hline Ir. & $\Delta$ & r & 9 & لولههاى خطوط ايستخاه \\
\hline $11 \mathrm{~T}$ & f & f & v & سنسينَ ها \\
\hline r. & f & $\Delta$ & r & ر كولاتور \\
\hline 14. & f & $\Delta$ & $\checkmark$ & 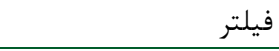 \\
\hline
\end{tabular}

از سوى ديخر، ويزگى خاص تشديد بروز انواع حوادث فاجعهبار

در سيستمهاى تكنولوزىمحور مانند بروز حريق و انفجار در خطوط

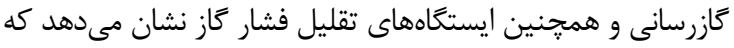

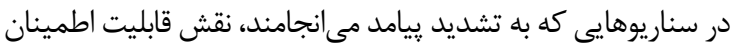

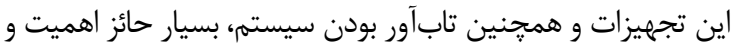

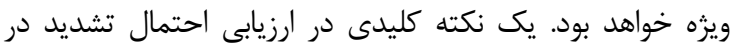

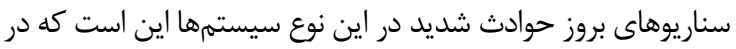


توسط نصب لايههاى حفاظتى و اقدامات اضطرارى مناسب اصلاح

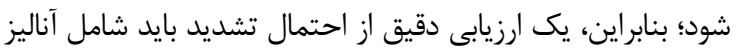

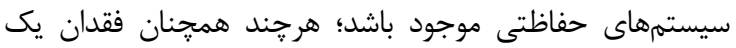

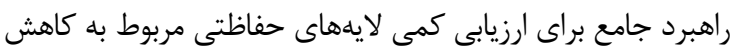

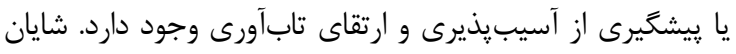



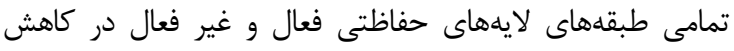

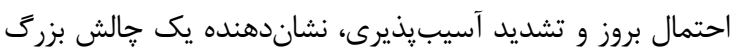

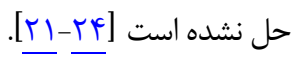
نتايج تحليل و ارزيابى آسيبذيذيرى منابع خطر و تهديد شناسايى شده مرتبط با حيطههاى مورد مطالعه در ايستخاههاى

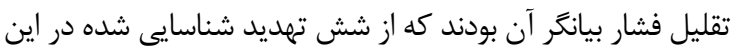

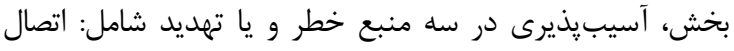

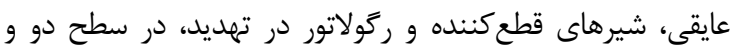

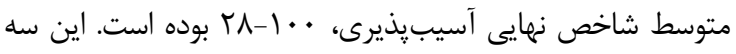

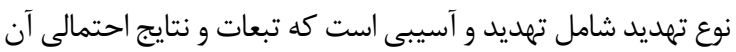

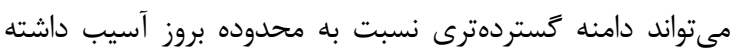

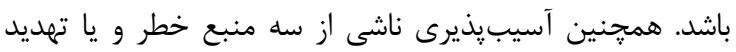

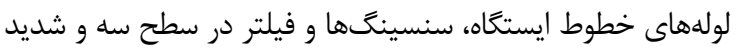

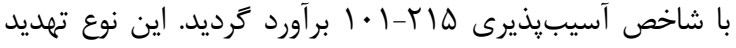



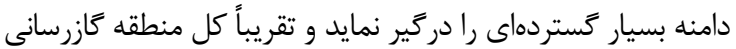

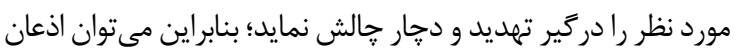

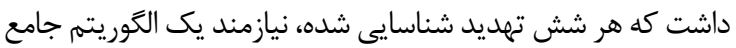

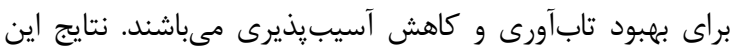

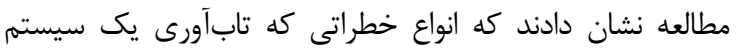

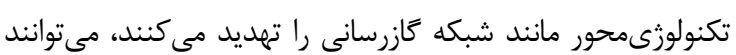

ارزيابى آسيبيذيرى در اين مطالعه ارائه شدهاند. نتايج ارزيابى

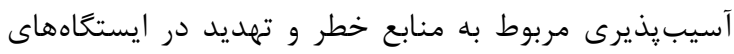

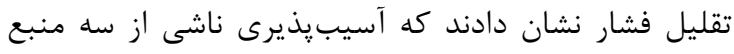

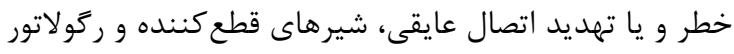

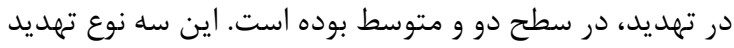

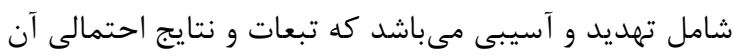

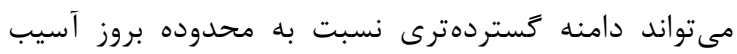

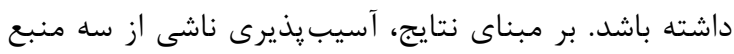

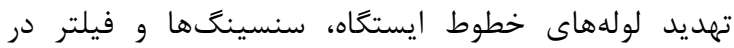

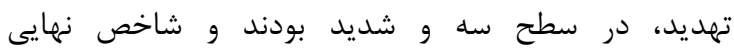

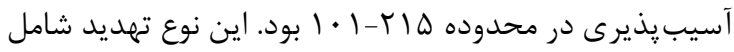

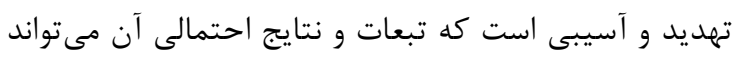

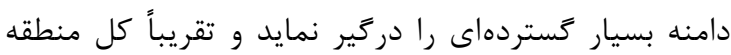
Fازرسانى مورد مطالعه را تهديد كند.

آسيبذيذيرى در سيستمهاى تكنولورىمحور تحت تأثير ارزيابى حفي

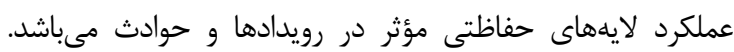

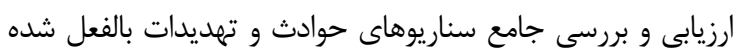

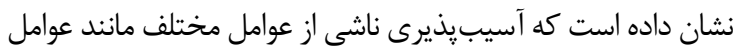

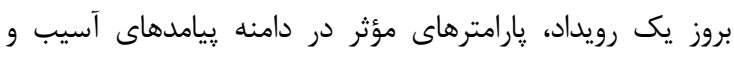

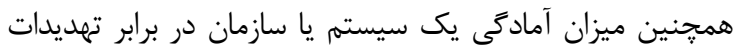

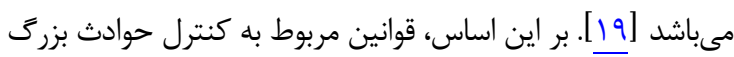

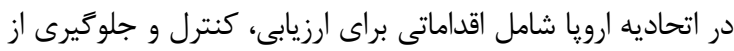

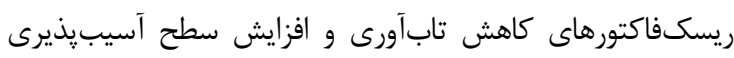

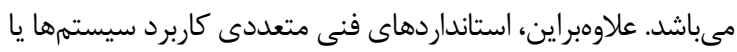

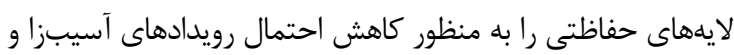

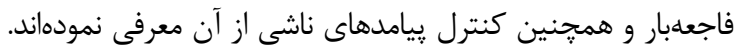

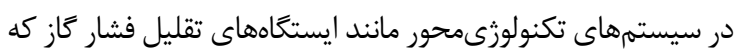
جنين خطرى در آنها وجود دارد، حفاظت از زيرسيستمها و و



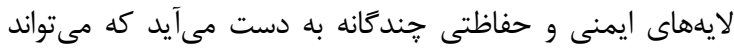

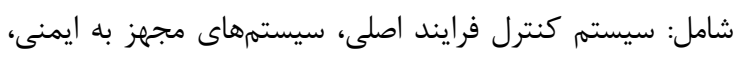

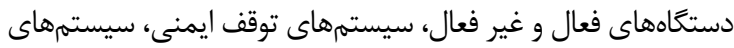

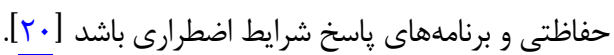


مبتنى بر ارزيابى آسيبذيذيرى و منطبق بر تهديدات مختلف در يك

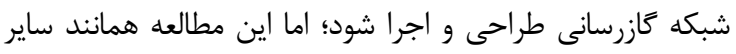
يزوهشها داراى برخى از محدوديتها از جمله بررسى ايستگًاههاى

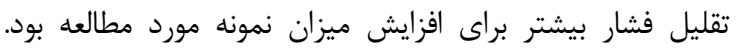
״يشنهاد مى گردد يزوهشهايى در زمينه طراحى مطالعات يِيجيدهتر

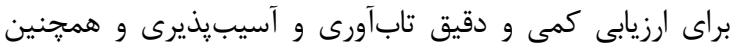

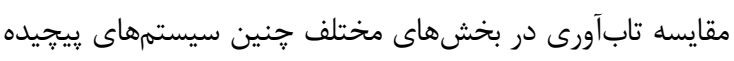
تكنولوزى محورى انجام شود.

\section{نتيجه تيرى}

يافتههاى اين مطالعه شامل شناسايى تهديدات و تعيين نقاط

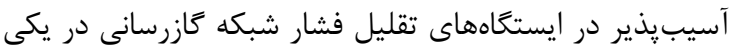

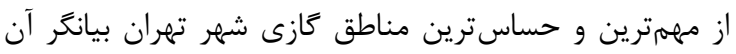

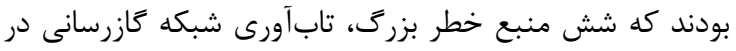

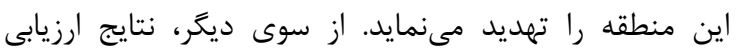

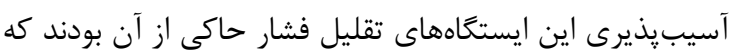

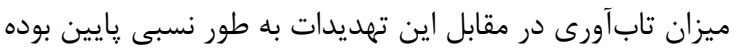

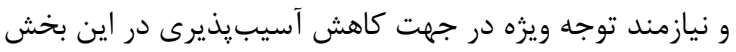

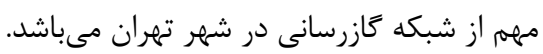

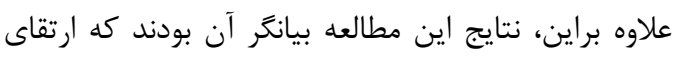

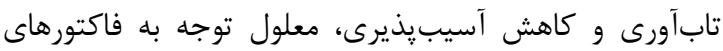



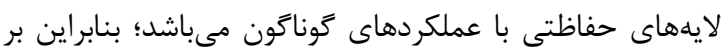

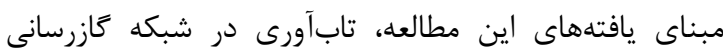
مىبايست با مدلهايى مانند آنجه در اين مطالعه مورد ارزيابى و

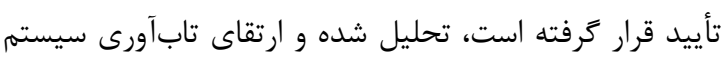



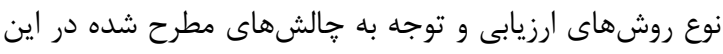
نوع تحليلها ارتقا و بهبود يابد.

اين مطالعه بركرفته از رساله دكترى مصوب دانشعاه آزاد

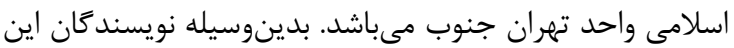

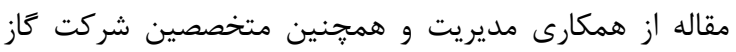

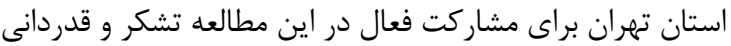
مىنمايند.

تعارض منافع نويسندكان در اين مطالعه تعارض منافعى نداشتهاند.

\section{ملاحظات اخلاقى}

در اين مطالعه هيج داده انسانى جمع آورى نشده است. بعلاوه، اطلاعات فردى افراد شركت كننده با رعايت محرمانكى دهى اده إنى
ناشى از بروز انواع نقص يا كاهش عملكرد در اتصال عايقى، شيرهاى

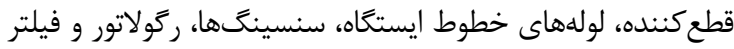

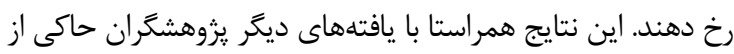

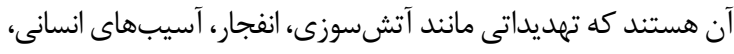

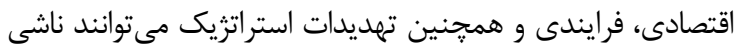

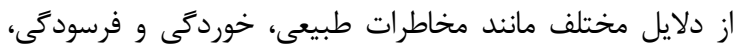

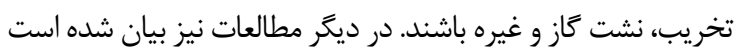

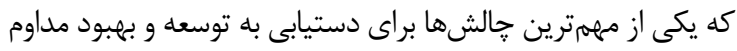

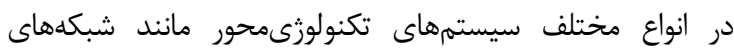

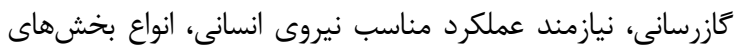

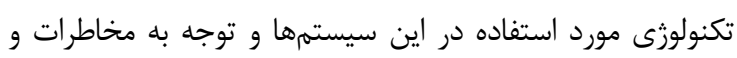

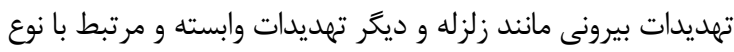

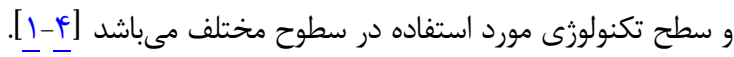

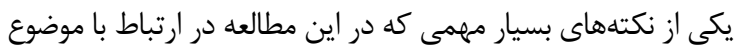

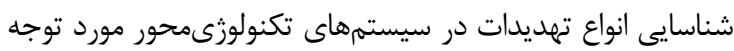

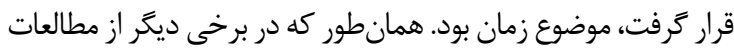

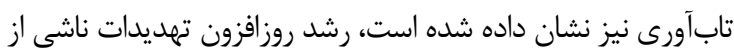
كذشت زمان مىباشد [عr، تهاب].

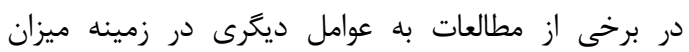

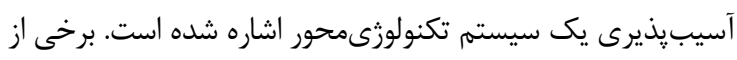
اين دلايل و عوامل عبارت هستند از: مخاطرات طبيعى مانند قرار

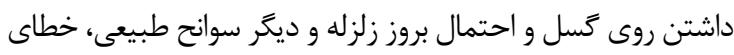

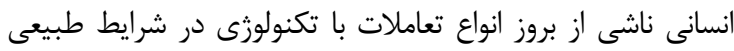

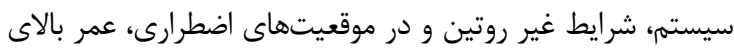
تجهيزات، كذشت زمان و كاهش قابليت اطمينان نسبت به سيس سيستم

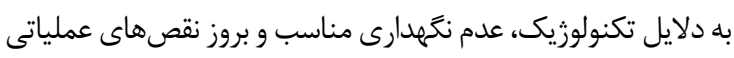

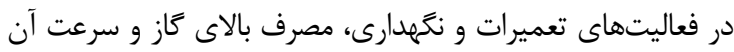

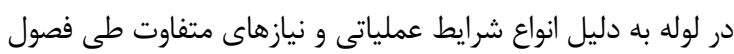
مختلف، انواع نقصهاى كمى و كيفى مرتبط با شير اطمينان و

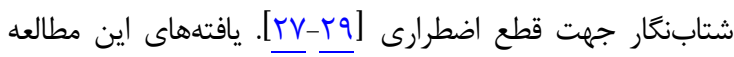

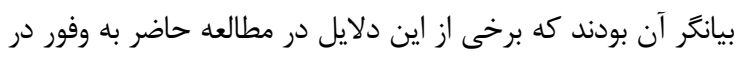

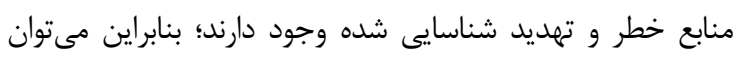

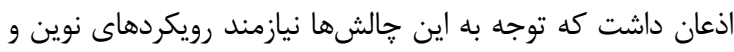

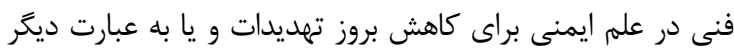

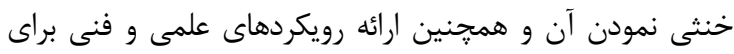
كاهش آسيبيذيرى و يا افزايش ميزان تابآورى يك هين سيستم

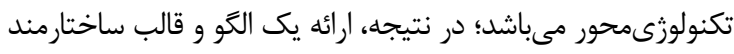

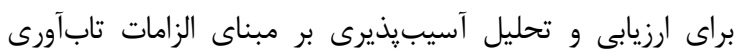

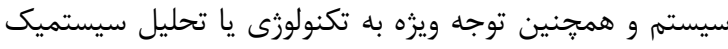

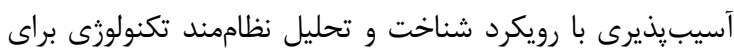

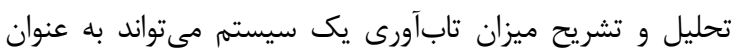

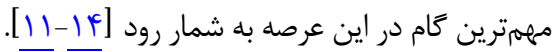

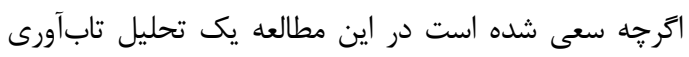




$$
\text { "حايان نامه و مقاله }
$$

\author{
حفظ شده است. \\ اسماعيل شجاع: كردآورى پايان نامه و تهيه كننده مقاله \\ محمد حسن خراغعلى: استاد راهنما در تهيه يايان نامه و مقاله \\ عليرضا رزقى رستمى و عليرضا درخشانى: استاد مشاور در تهيه
}

\section{REFERENCES}

1. Haimes $Y Y$. On the definition of resilience in systems. Risk Anal. 2009;29(4):498-501. PMID: 19335545 DOI: 10.1111/j.1539-6924.2009.01216.x

2. Barker $K$, Haimes $Y Y$. Assessing uncertainty in extreme events: applications to risk-based decision making in interdependent infrastructure sectors. Reliabil Eng Syst Saf. 2009;94(4):819-29. DOI: 10.1016/j.ress.2008.09.008

3. Dinh LT, Pasman H, Gao X, Mannan MS. Resilience engineering of industrial processes: principles and contributing factors. J Loss Prev Proc Ind. 2012;25(2):23341. DOI: 10.1016/i.jlp.2011.09.003

4. Knegtering B, Pasman H. Safety of the process industries in the 21st century: a changing need of process safety management for a changing industry. J Loss Prev Proc Ind. 2009;22(2):162-8. DOI: 10.1016/j.jlp.2008.11.005

5. Jing $Y$, Jianming $C$, Hong $Z$. The classification of emergency in incident management [J]. Manag Rev. 2005;4:37-41.

6. Fuchs $S$, Heiss $K$, Hübl J. Towards an empirical vulnerability function for use in debris flow risk assessment. Natl Hazards Earth Syst Sci. 2007;7(5):495-506. DOI: 10.5194/nhess-7495-2007

7. Lees F. Lees' Loss prevention in the process industries: Hazard identification, assessment and control. Oxford: Butterworth-Heinemann; 2012.

8. Gholamizadeh K, Kalatpour O, Mohammadfam I. Evaluation of health consequences in chemicals road transport accidents using a fuzzy approach. J Occup Hyg Eng. 2019;6(3):1-8. DOI: 10.29252/johe.6.3.1

9. Mohammadfam I, Shokouhipour A, Zamanparvar A. A framework for assessment of intentional fires. J Occup Hyg Eng. 2014;1(1):16-25.

10. Maddah S, Bidehendi GN, Taleizadeh AA, Hoveidi H. A framework to evaluate health, safety, and environmental performance using resilience engineering approach: a case study of automobile industry. J Occup Hyg Eng Volume. 2020;6(4):50-8. DOI: 10.29252/johe.6.4.50

11. Barker K, Ramirez-Marquez JE, Rocco CM. Resilience-based network component importance measures. Reliabil Eng Syst Saf. 2013;117:89-97. DOI: 10.1016/j.ress.2013.03.012

12. Béné C, Wood RG, Newsham A, Davies M. Resilience: new utopia or new tyranny? Reflection about the potentials and limits of the concept of resilience in relation to vulnerability reduction programmes. IDS Work Papers. 2012;2012(405):1-61. DOI: $\quad$ 10.1111/j.20400209.2012.00405.x

13. Paton D, Johnston D. Disasters and communities: vulnerability, resilience and preparedness. Disaster Prev Manag. 2001; 10(4):270-7. DOI: 10.1108/EUM0000000005930

14. Adger WN. Vulnerability. Global Environ Change. 2006;16(3):268-81. DOI: 10.1016/j.gloenvcha.2006.02.006

15. Zio E. Challenges in the vulnerability and risk analysis of critical infrastructures. Reliabil Eng Syst Saf. 2016;152:13750. DOI: 10.1016/j.ress.2016.02.009

16. Coburn A, Spence R, Pomonis A. Guide to vulnerability and risk assessment. Disaster management training programme (DMTP). Cambridge: Cambridge Architectural Research Limited; 1994.

17. Sarewitz D, Pielke R Jr, Keykhah M. Vulnerability and risk: some thoughts from a political and policy perspective. Risk Anal. 2003;23(4):805-10. PMID: 12926572 DOI: 10.1111/1539$\underline{6924.00357}$

18. Khakzad N, Reniers $G$, Abbassi $R$, Khan F. Vulnerability analysis of process plants subject to domino effects. Reliabil Eng Syst Saf. 2016;154:127-36. DOI: 10.1016/j.ress.2016.06.004

19. Zhao R, Liu $S$, Liu Y, Zhang L, Li Y. A safety vulnerability assessment for chemical enterprises: a hybrid of a data envelopment analysis and fuzzy decision-making. J Loss Prev Proc Ind. 2018;56:95-103. DOI: 10.1016/j.jlp.2018.08.018

20. Tie-min LI. Recognition of disaster causes-study of the vulnerability. J Saf Sci Technol. 2010;7:5.

21. Sklet S. Safety barriers: definition, classification, and performance. J Loss Prev Proc Ind. 2006;19(5):494-506. DOI: 10.1016/j.jlp.2005.12.004

22. Tanabe $M$, Miyake A. Approach enhancing inherent safety application in onshore LNG plant design. J Loss Prev Proc Ind. 2012;25(5):809-19. DOI: 10.1016/j.jlp.2012.04.005

23. Rausand M. Reliability of safety-critical systems. Hoboken: John Wiley \& Sons; 2014.

24. Shahedi Ali Abadi S, Assari MJ, Kalatpour O, Zarei E, Mohammadfam I. Consequence modeling of fire on Methane storage tanks in a gas refinery. J Occup Hyg Eng. 2016;3(1):51-9. DOI: 10.21859/johe-03017

25. Patterson M, Deutsch ES. Safety-I, safety-II and resilience engineering. Curr Probl Pediatr Adolesc Health Care. 2015; 45(12):382-9. PMID: 26549146 DOI: 10.1016/j.cppeds. 2015.10.001

26. Gaitanidou E, Tsami M, Bekiaris E. A review of resilience management application tools in the transport sector. Transport Res Proc. 2017;24:235-40. DOI: 10.1016/j.trpro.2017.05.113

27. Pariès J. Complexity, emergence, resilience. Resilience engineering. Florida: CRC Press; 2017. P. 43-53.

28. Hollnagel E, Nemeth CP, Dekker S. Resilience engineering perspectives: remaining sensitive to the possibility of failure. Farnham: Ashgate Publishing, Ltd.; 2008.

29. Leveson N, Dulac N, Zipkin D, Cutcher-Gershenfeld J, Carroll J, Barrett B. Engineering resilience into safetycritical systems. Resilience engineering: concepts and precepts. Farnham: Ashgate Publishing, Ltd.; 2006. P. 95-123. 